Case Report

\title{
Clinical Lessons to Be Learned from Patients Developing Chronic Myeloid Leukemia While on Immunosuppressive Therapy after Solid Organ Transplantation: Yet Another Case after Orthotopic Heart Transplantation
}

\author{
Christian Oberender, ${ }^{1}$ Lorenz Kleeberg, ${ }^{1}$ Nicola Nienhues, ${ }^{2}$ Martin Gresse, ${ }^{3}$ \\ Bernd Dörken, ${ }^{3}$ Hanno Riess, ${ }^{1,3}$ and Philipp le Coutre ${ }^{1,3}$ \\ ${ }^{1}$ Medizinische Klinik mit Schwerpunkt Hämatologie und Onkologie, Universitätsmedizin Berlin, Campus Mitte Charité, \\ Schumannstraße 20/21, 10117 Berlin, Germany \\ ${ }^{2}$ Deutsches Herzzentrum Berlin, Abteilung für Herz-, Thorax- und Gefäßchirurgie, Augustenburger Platz 1, 13353 Berlin, Germany \\ ${ }^{3}$ Medizinische Klinik mit Schwerpunkt Hämatologie, Onkologie und Tumorimmunologie, Universitätsmedizin Berlin, \\ Campus Virchow Charité, Augustenburger Platz 1, 13353 Berlin, Germany
}

Correspondence should be addressed to Philipp le Coutre; philipp.lecoutre@charite.de

Received 31 August 2014; Revised 23 October 2014; Accepted 24 October 2014; Published 16 November 2014

Academic Editor: Kazunori Nakase

Copyright (C) 2014 Christian Oberender et al. This is an open access article distributed under the Creative Commons Attribution License, which permits unrestricted use, distribution, and reproduction in any medium, provided the original work is properly cited.

Chronic myeloid leukemia developing after transplantation of solid organs and concomitant immunosuppression is a rare but still significant clinical phenomenon. We here describe an additional case of a 62-year-old male patient developing CML after orthotopic heart transplantation and medication with cyclosporine A, mofetil-mycophenolate, and steroids. Initial antileukemic therapy was imatinib at a standard dose and within 15 months of therapy a complete cytogenetic response was noted. In this report we discuss the clinical implications of these rare but biologically important cases.

\section{Introduction}

Secondary malignancies following solid organ transplantation (SOT) and immunosuppressive therapy are becoming an emerging issue as total transplant numbers are increasing, the overall survival of organ recipients is improving, and an increasing proportion of organ recipients is of older age, when cancer is more often diagnosed. Probably, the best studied scenario in this setting is the association of EBV and posttransplantation lymphoproliferative diseases [1]. But also squamous cell carcinomas and Kaposi sarcomas as well as specific myeloid malignancies, notably myelodysplastic syndromes and acute myeloid leukemia, have been observed more frequently in patients following solid organ transplantation $[2,3]$. In addition, after the first report by Battin et al. (1976), a remarkable number of case reports describing cases of chronic myeloid leukemia (CML) following solid organ transplantation and immunosuppression were published over the past decades ([4-27], Table 1).

In CML the BCR-ABL1 fusion gene, caused by a typical $\mathrm{t}(9 ; 22)$ (q34;q11) chromosomal translocation, is the pathogenic driver of the disease leading to enhanced proliferation and left shift but also is used as a target to monitor minimal residual disease by quantitative reverse-transcription quantitative polymerase chain reaction (rt-PCR) analyses [28]. On the protein level, the bcr-abl ${ }^{\mathrm{p} 210}$ oncoprotein has become the target structure for specific therapies by tyrosine kinase inhibitors such as imatinib, nilotinib, and/or dasatinib in the first-line setting and additionally bosutinib and ponatinib beyond initial treatment [29]. There are conflicting data whether BCR-ABL1 is the only oncogenic lesion that is needed to cause chronic phase CML or if other, yet unidentified, mutations are involved. In this regard the sporadic identification of low levels of BCR-ABL1 transcripts in healthy 


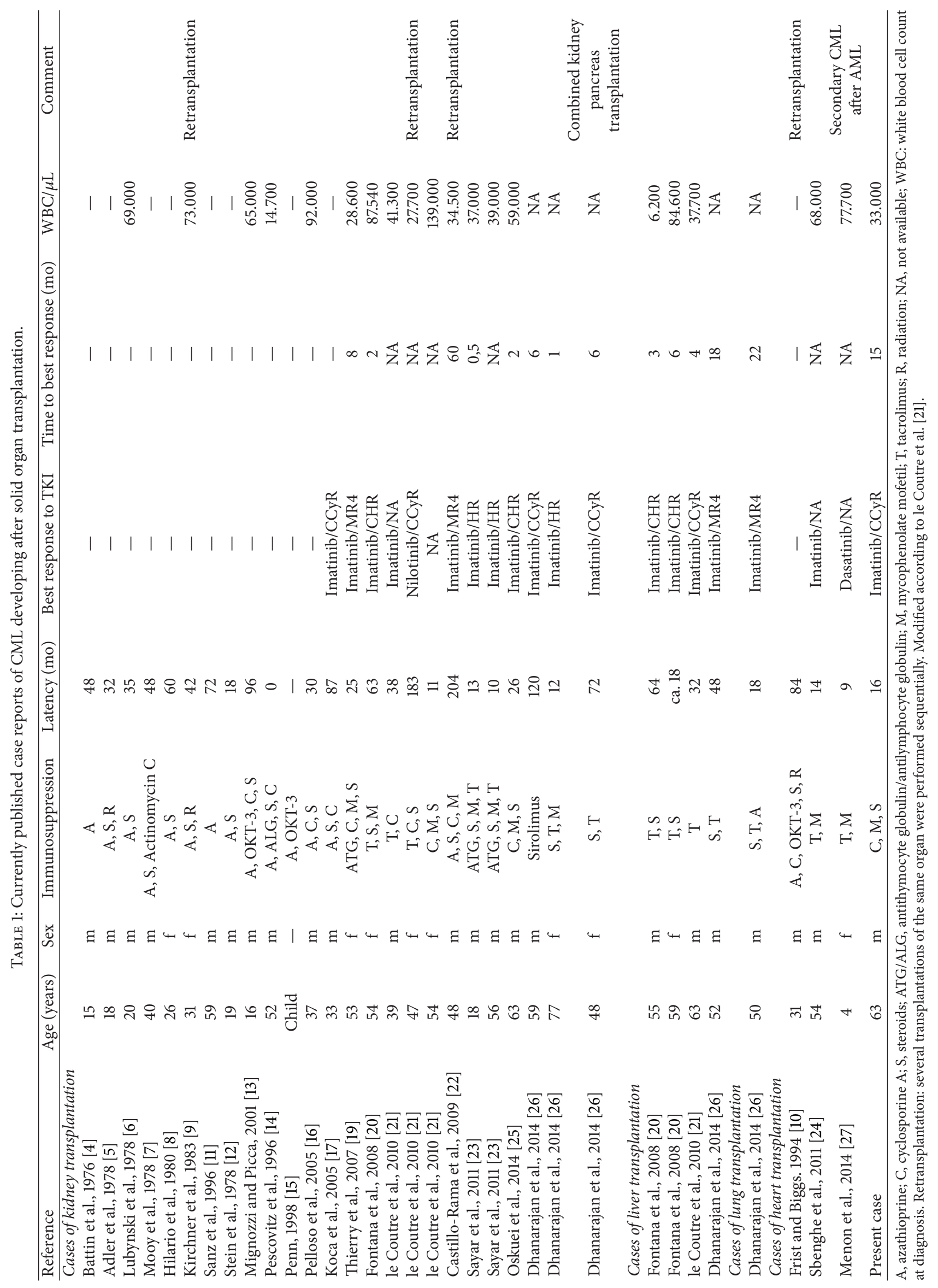


individuals was of note [30,31]. The general interpretation of these findings was that in healthy individuals the occurrence of oncogenic mutations, including BCR-ABL1, may occur but is under the control of an effective immune surveillance.

Thus, CML developing in patients following SOT may be triggered by the effects of concomitant application of immunosuppressive drugs. In line with this hypothesis we previously compared by rt-PCR the BCR-ABLl status in patients following SOT but without CML and indeed detected 5\% low-level PCR positivity in these patients as compared to none in a control group without immunosuppression [21]. Finally, in a recently published article the risk to develop CML in patients after SOT was calculated to be more than 20 -fold higher as in the normal population [26].

In this paper we describe another patient with chronic phase CML following orthotopic heart transplantation and immunosuppression. As in our previous article we discussed the various biological mechanisms that may contribute to CML following immunosuppression; we here provide an overview on all published cases and focus on individual aspects of the clinical management in this specific cohort [21].

\section{Case Presentation}

We here report on a caucasian male with dilated cardiomyopathy, who underwent in November 2010 as a 61-yearold patient an orthotopic bicaval heart transplantation at the Deutsches Herzzentrum Berlin following left ventricular assist device (HeartMate II) implantation in September 2009 due to cardiogenic shock. Due to impaired graft function a primary intra-aortic balloon pump was implanted. Transplantation was done in a CMV-positive recipient with a heart graft from a CMV-positive donor. Induction therapy was performed using Thymoglobulin $(1.5 \mathrm{mg} / \mathrm{kg})$. Posttransplant maintenance immunosuppressive therapy consisted of cyclosporine A $(4 \mathrm{mg} / \mathrm{kg})$, mofetil-mycophenolate $(2-3 \mathrm{~g}$ daily), and prednisolone (tapering regimen, $0.15 \mathrm{mg} / \mathrm{kg}$ ). Concomitant medication included pantozol, amlodipine, ramipril, magnesium, allopurinol, torasemide, fluvastatine, and Ca-D3. Two serologic CMV replications were treated with ganciclovir i.v. The cardiovascular risk profile prior to transplantation included tobacco use, arterial hypertension, and male gender.

During a routine follow-up visit in March 2013 leukocytosis of $33.000 / \mu \mathrm{L}$, thrombocytosis of $655.000 / \mu \mathrm{L}$, and anemia of $11.2 \mathrm{~g} / \mathrm{dL}$ were noted. The differential blood count was myelocytes $6 \%$, metamyelocytes $2 \%$, bands $5 \%$, segmented granulocytes $75 \%$, eosinophils $2 \%$, basophils $2 \%$, monocytes $5 \%$, and lymphocytes $3 \%$. Accordingly, a bone marrow analysis was done that revealed elevation of megakaryocytes and a disbalance between granulopoiesis and erythropoiesis of $4: 1$ but no elevation of blasts or promyelocytes. Conventional cytogenetics analysis demonstrated the typical $\mathrm{t}(9 ; 22)(\mathrm{q} 34 ; \mathrm{q} 11)$ translocation in all analysed nuclei and a multiplex PCR confirmed the presence of BCR-ABL transcripts establishing the diagnosis of chronic phase chronic myeloid leukemia. No hepatosplenomegaly was present allocating this patient into the low-risk category by EUTOS-score [28].
As there are currently three tyrosine kinase inhibitors (imatinib, nilotinib, and dasatinib) with approval for the firstline treatment of CML, the choice of therapy was primarily made on the basis of the individual tolerability profile. As nilotinib is associated with a cardiovascular risk and dasatinib is linked to pleural and pericardial effusion and pulmonary artery hypertension, imatinib $400 \mathrm{mg}$ was chosen [32, 33].

Imatinib was well tolerated and within 3 months normalisation of peripheral blood cell counts, compatible with a complete hematologic response, was observed. At the time of CML diagnosis maintenance immunosuppression was switched to a double regimen (cyclosporine $\mathrm{A}$ trough level $100-120 \mathrm{ng} / \mathrm{mL}$ and prednisolone $0.15 \mathrm{mg} / \mathrm{kg}$ ). A bone marrow analysis taken 15 months after start of imatinib showed a complete cytogenetic remission. However, in 10 out of 25 otherwise normal analysed metaphases a loss of the $y$ chromosome was detected. So far, imatinib is well tolerated in this patient without any drug related adverse events.

Echocardiographic examinations done at diagnosis of CML and 14 months after initiation of imatinib documented a left ventricular ejection fraction of at least $60 \%$ indicating no cardiotoxicity of tyrosine kinase inhibitor therapy.

\section{Discussion}

The development of hematologic malignancies is a rare clinical complication in the post- organ-transplant population and most frequently occurs as Non-Hodgkin-Lymphoma (PTLD).

Since the first description by Battin et al. (1976) altogether 34 patients developing CML after SOT were reported, primarily as case reports, and 15 of these cases were published within the past 5 years, indicating a growing interest in this phenomenon [4-27]. In a most recent report the frequency of CML developing in SOT patients was calculated relating the total transplant numbers in a single centre and the number of CML cases observed in this group of patients to the age- and gender-matched US population [26]. Despite the low denominator of 3089 individuals in this study an age adjusted incidence rate of 34.7 per 100000 was observed that significantly $(P<0.0001)$ exceeds the US incidence of 1.6 per 100000 [26]. Thus, under the assumption that SOT carries an elevated risk of CML, these numbers will eventually increase in the future as both the total number of transplants and the age of organ recipients are increasing.

Generally, two types of mechanisms must be differentiated in the clinical setting of a de-novo posttransplant malignancy: (1) the unfrequent cases of preexisting malignancies that are transferred with the donor organ and (2) malignancies manifesting after initiation of immunosuppressive therapy. In the first case HLA-typing or molecular clonal testing of neoplastic tissue can be applied to rule out donor derived neoplasms while in the latter case the exact pathomechanism is not understood but impaired immune surveillance together with intrinsic mutagenic potential may play a significant role. But also the effect of either infectious (viral) or toxic (immune suppressive drugs) factors could contribute as an extrinsic cause of transformation. In this 
regard the observation of DNA lesions caused by azathioprine in combination with UVA radiation is of note [34]. Still, the exact role of the immunosuppressive drugs in the evolution of posttransplantation malignancies needs to be elucidated, but it is of interest that these cases continue to appear while azathioprine is being more and more replaced by alternative drugs such as mycophenolate mofetil and tacrolimus.

Several aspects in the setting of CML developing after SOT are of note.

With the various tyrosine kinase inhibitors that are currently available for the first-line treatment the prognosis of CML has improved dramatically over the past 15 years [28]. To what extent the specific clinical setting of patients with CML following SOT may impact response is unclear. Certainly, the underlying disease leading to transplantation, potential drug interactions, and a potentially low clinical performance status could negatively impact response and survival rates in individual patients. On the other hand due to the more frequent visits of patients following SOT patients developing CML may eventually be recognised earlier and already at a lower risk. This hypothesis is reflected by the observation that in our patient as well as in many of the currently published cases WBC were relatively low $(<35.000$ per $\mu \mathrm{L}$ ) when $\mathrm{CML}$ was diagnosed (Table 1).

Probably because of relative short follow-up intervals in none of the reports presented here deep molecular responses that would allow drug discontinuations were reported. However, as immunological mechanisms are currently discussed to be involved in patients stopping TKI therapy after longterm molecular remission, we hypothesize that in patients with CML following immunosuppression fewer patients would remain BCR-ABL negative after discontinuation as long as immunosuppression is continued.

To our knowledge we here describe the fourth patient with CML following heart transplantation and the third case of this kind that was treated with a tyrosine kinase inhibitor $[10,24]$. But other than in the cases reported by Sbenghe et al. and Menon et al. who received tacrolimus in addition to mofetil-mycophenolate in our case cyclosporine was given [24, 27]. However, the significance of the various immunosuppressive drugs given in these patients is still unclear. The case reported by Menon et al. is of specific interest as it describes a secondary CML developing after acute myeloid leukemia [27]. In this pediatric case heart transplantation was carried out because of anthracyclineinduced cardiomyopathy [27]. With the exception of a past case by Frist et al. all other cases of CML following heart transplantation are characterized by a relatively short latency of 9 to 16 months $[10,24,27]$. This observation could be associated to the relatively dose intensive immunosuppressive regimens used in heart transplantation.

Most of the published cases were treated with imatinib as first-line TKI. In general, all three currently approved first-line options (imatinib, nilotinib, and dasatinib) can be chosen as well in SOT patients. However, as the toxicity profiles of the second generation TKIs dasatinib and nilotinib include immunosuppression, atherosclerotic events, pulmonary artery hypertension, and pleural effusion, an initial trial with imatinib, despite its less favourable response rates, may be the preferred treatment option in many of these patients $[32,33]$. As in our patient numerous cardiovascular risk factors were present and already a major cardiac intervention was performed, we also preferred imatinib over a second generation TKI as first-line option.

In summary, CML following immunosuppressive therapy beyond its clinical implications is an interesting model of immune surveillance in tumor biology. As there are only few cases of $\mathrm{Phl}$ chromosome negative chronic myeloproliferative neoplasms arising after immunosuppression, we suspect this phenomenon to be specifically linked to CML. We believe that both preclinical and clinical investigations that address the specific mechanisms of immunosuppressive drugs and the acquisition of the $t(9 ; 22)(q 34 ; q 11)$ could be of interest.

\section{Conflict of Interests}

The authors declare that there is no conflict of interests regarding the publication of this paper.

\section{References}

[1] H. Zimmermann and R. U. Trappe, "EBV and posttransplantation lymphoproliferative disease: what to do?" Hematology, vol. 2013, no. 1, pp. 95-102, 2013.

[2] D. Ondruš, V. Pribylincová, J. Breza et al., "The incidence of tumours in renal transplant recipients with long-term immunosuppressive therapy," International Urology and Nephrology, vol. 31, no. 4, pp. 417-422, 1999.

[3] L. M. Morton, T. M. Gibson, C. A. Clarke et al., "Risk of myeloid neoplasms after solid organ transplantation," Leukemia, 2014.

[4] J. Battin, J. P. Hehunstre, N. B. Bui, J. Auzerie, and M. Colle, "Chronic myeloid leukaemia after immunosuppressive treatment for chronic nephropathy," La Nouvelle Presse Médicale, vol. 5, p. 2632, 1976.

[5] K. R. Adler, N. Lempert, and W. B. Scharfman, "Chronic granulocytic leukemia following successful renal transplantation," Cancer, vol. 41, no. 6, pp. 2206-2208, 1978.

[6] R. Lubynski, A. M. Meyers, P. B. Disler, A. P. MacPhail, J. A. Myburgh, and J. Katz, "Chronic granulocytic leukemia in a patient with a renal allograft," Archives of Internal Medicine, vol. 138, no. 9, pp. 1429-1430, 1978.

[7] J. M. V. Mooy, J. C. W. Hagenouw-Taal, L. D. F. Lameijer, and J. M. Van Turnhout, "Chronic granulocytic leukemia in a renal transplant recipient," Cancer, vol. 41, no. 1, pp. 7-9, 1978.

[8] R. Hilario, T. Padre-Mendoza, and M. M. Albala, "Chronic granulocytic leukemia and carcinoma of the cervix in situ following renal transplantation," The American Journal of the Medical Sciences, vol. 280, no. 2, pp. 115-118, 1980.

[9] K. A. Kirchner, J. C. Files, R. Didlake, S. Raju, and R. P. Krueger, "Chronic granulocytic leukemia after renal transplantation," Archives of Internal Medicine, vol. 143, no. 10, pp. 1984-1987, 1983.

[10] W. H. Frist and V. J. Biggs, "Chronic myelogenous leukemia after lymphoid irradiation and heart transplantation," Annals of Thoracic Surgery, vol. 57, no. 1, pp. 214-216, 1994.

[11] L. Sanz, F. Cervantes, J. Esteve et al., "Chronic myeloid leukaemia after renal transplantation: report of a new case and review of the bibliography," Sangre, vol. 41, no. 5, pp. 391-393, 1996. 
[12] A. M. Stein, R. Anthone, S. Anthone, M. J. Marinello, C. M. Elwood, and R. M. Bannerman, "Chronic myelocytic leukemia in a young renal allografted patient," Transplantation, vol. 26, no. 4, pp. 271-273, 1978.

[13] M. Mignozzi and S. Picca, "Chronic myelogenous leukemia following kidney transplantation in a pediatric patient," Pediatric Nephrology, vol. 16, no. 11, pp. 852-853, 2001.

[14] M. D. Pescovitz, N. A. Heerema, R. M. Jindal, M. L. Milgrom, S. B. Leapman, and R. S. Filo, "The natural history of chronic myelogenous leukemia in a renal transplant recipient," Transplantation, vol. 61, no. 2, pp. 328-331, 1996.

[15] I. Penn, "De novo malignances in pediatric organ transplant recipients," Pediatric Transplantation, vol. 2, no. 1, pp. 56-63, 1998.

[16] L. A. F. Pelloso, M. G. Vaz De Campos, M. Nascimento, M. R. R. Silva, J. O. M. Pestana, and M. D. L. L. F. Chauffaille, "Chronic myeloid leukemia following kidney transplantation," Leukemia Research, vol. 29, no. 3, pp. 353-355, 2005.

[17] E. Koca, D. Cetiner, H. Goker et al., "Complete cytogenietic remission with imatinib mesylate treatment in chronic myelogenous leukemia (CML) developed after renal transplantation," Clinical Nephrology, vol. 64, no. 4, pp. 324-326, 2005.

[18] A. Concejero, C.-L. Chen, C.-C. Wang et al., "Chronic myeloid leukemia after living donor liver transplantation," Transplantation, vol. 83, no. 11, pp. 1521-1522, 2007.

[19] A. Thierry, B. Dreyfus, F. Bridoux et al., "Long-term molecular efficacy and safety of imatinib in a patient with chronic myeloid leukaemia after renal transplantation," Nephrology Dialysis Transplantation, vol. 22, no. 6, pp. 1791-1792, 2007.

[20] V. Fontana, P. Dudkiewicz, L. L. Horstman, A. G. Tzakis, and Y. S. Ahn, "A typical chronic myeloid leukemia following organ transplants," Clinical Transplantation, vol. 22, no. 2, pp. 258-261, 2008.

[21] P. Le Coutre, P. Reinke, R. Neuhaus et al., "BCR-ABL positive cells and chronic myeloid leukemia in immune suppressed organ transplant recipients," European Journal of Haematology, vol. 84, no. 1, pp. 26-33, 2010.

[22] M. Castillo-Rama, C. Grande, P. Martinez-Sánchez et al., "Remisión molecular de una leucemia mieloide crónica en un paciente con Segundo trasplante renal y hepatitis," Nefrologia, vol. 6, pp. 604-607, 2009.

[23] H. Sayar, A. A. Sharfuddin, T. E. Taber, and R. Mehta, "Chronic myeloid leukemia within a year of kidney transplant with elevated alkaline phosphatase correlated with imatinib therapy," Experimental and Clinical Transplantation, vol. 9, no. 5, pp. 336339, 2011.

[24] M. M. Sbenghe, A. D. Florea, P. Mather, and E. Gitelson, "Chronic myeloid leukemia following heart transplantation and immunosuppression with tacrolimus," Clinical Advances in Hematology and Oncology, vol. 9, no. 8, pp. 623-627, 2011.

[25] A. E. Oskuei, K. Makhdoomi, S. Abkhiz, S. Vossoghian, and M. Farrokhpour, "Successful treatment of chronic myelogenic leukemia (CML) with Imatinib after renal transplantation," Archives of Iranian Medicine, vol. 17, no. 5, pp. 388-390, 2014.

[26] A. Dhanarajan, J. W. Hsu, P. le Coutre, J. R. Wingard, M. Chang, and M. Norkin, "Elevated incidence of chronic myeloid leukaemia in immunosuppressed solid organ transplant recipients," British Journal of Haematology, vol. 166, no. 4, pp. 619-621, 2014.

[27] N. M. Menon, E. Katsanis, Z. Khalpey, and P. Whitlow, "Pediatric secondary chronic myeloid leukemia following cardiac transplantation for anthracycline-induced cardiomyopathy," Pediatric Blood - Cancer, 2014.

[28] S. Faderl, M. Talpaz, Z. Estrov, S. O’Brien, R. Kurzrock, and H. M. Kantarjian, "The biology of chronic myeloid leukemia," The New England Journal of Medicine, vol. 341, no. 3, pp. 164-172, 1999.

[29] M. Baccarani, M. W. Deininger, G. Rosti et al., "European LeukemiaNet recommendations for the management of chronic myeloid leukemia: 2013," Blood, vol. 122, no. 6, pp. 872-884, 2013.

[30] S. Bose, M. Deininger, J. Gora-Tybor, J. M. Goldman, and J. V. Melo, "The presence of typical and atypical BCR-ABL fusion genes in leukocytes of normal individuals: biologic significance and implications for the assessment of minimal residual disease," Blood, vol. 92, no. 9, pp. 3362-3367, 1998.

[31] C. Biernaux, M. Loos, A. Sels, G. Huez, and P. Stryckmans, "Detection of major bcr-abl gene expression at a very low level in blood cells of some healthy individuals," Blood, vol. 86, no. 8, pp. 3118-3122, 1995.

[32] K. J. Aichberger, S. Herndlhofer, G.-H. Schernthaner et al., "Progressive peripheral arterial occlusive disease and other vascular events during nilotinib therapy in CML," American Journal of Hematology, vol. 86, no. 7, pp. 533-539, 2011.

[33] D. Montani, E. Bergot, S. Günther et al., "Pulmonary arterial hypertension in patients treated by dasatinib," Circulation, vol. 125, no. 17, pp. 2128-2137, 2012.

[34] P. O’Donovan, C. M. Perrett, X. Zhang et al., "Medicine: Azathioprine and UVA light generate mutagenic oxidative DNA damage," Science, vol. 309, no. 5742, pp. 1871-1874, 2005. 


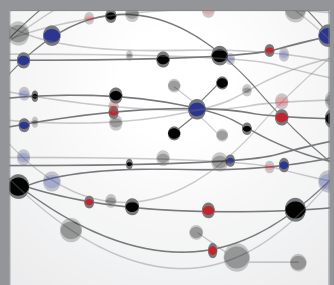

The Scientific World Journal
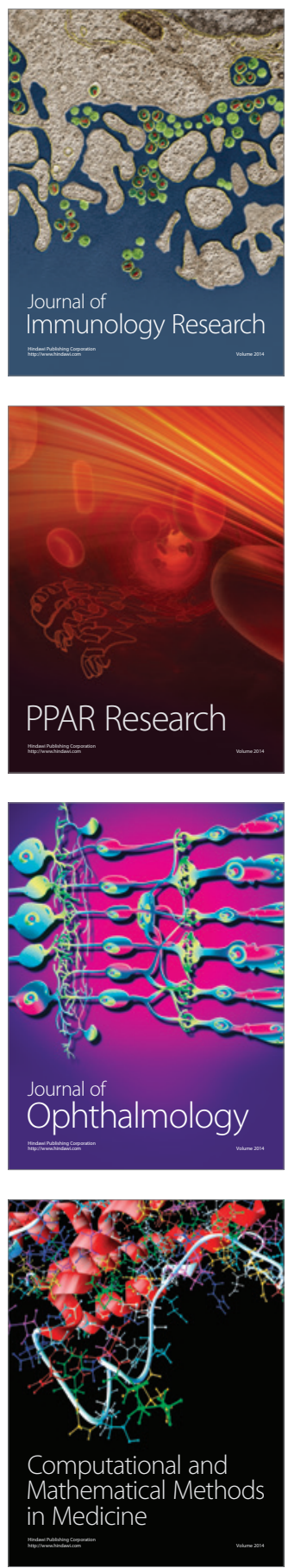

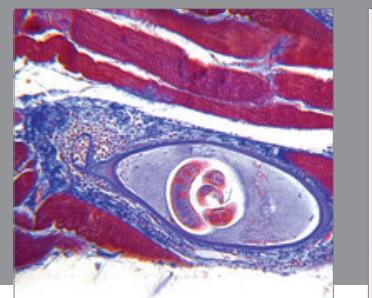

Gastroenterology

Research and Practice
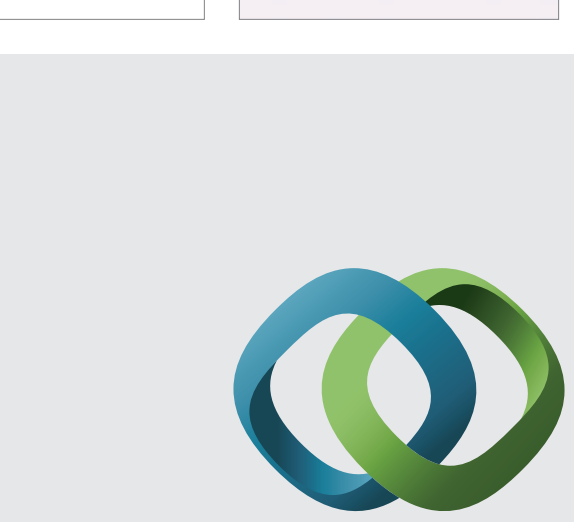

\section{Hindawi}

Submit your manuscripts at

http://www.hindawi.com
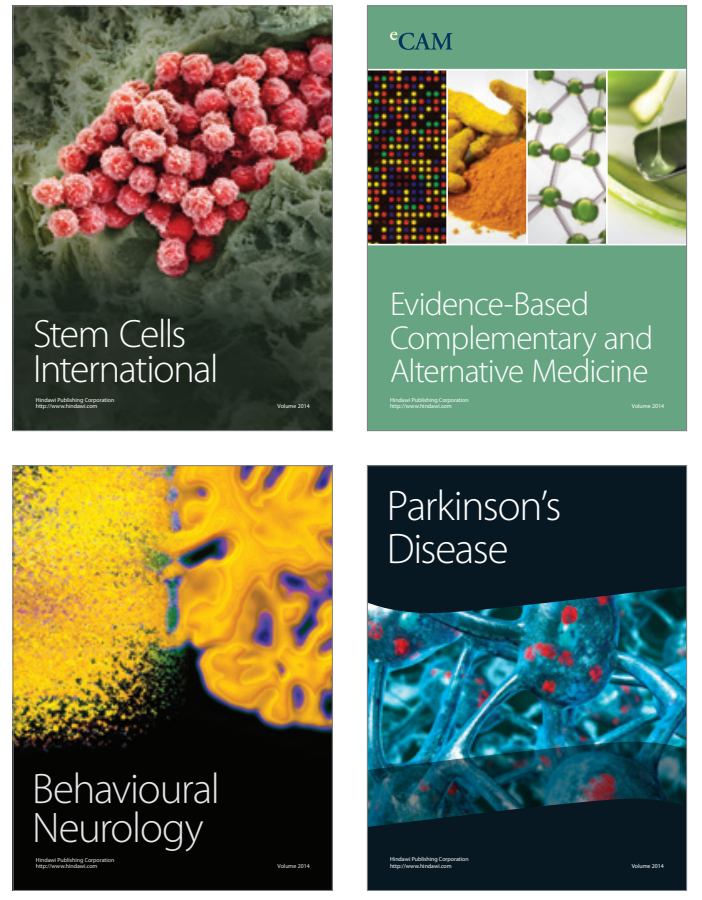
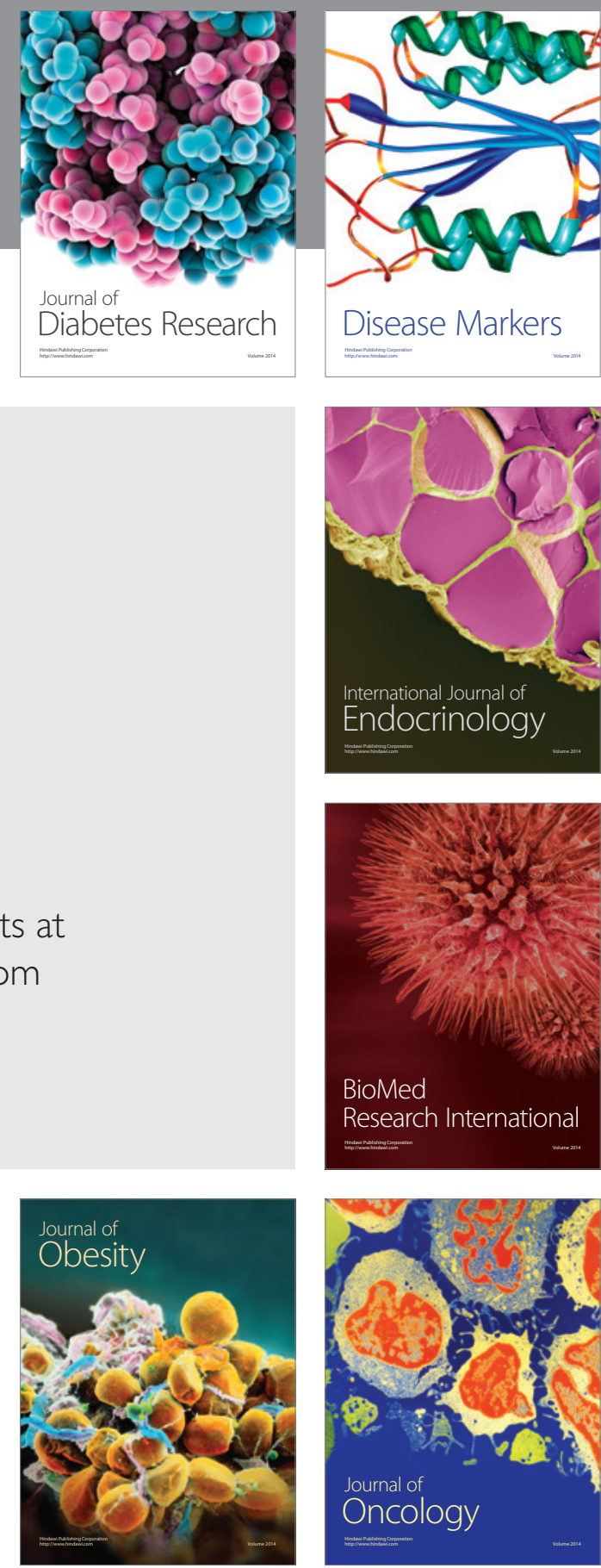

Disease Markers
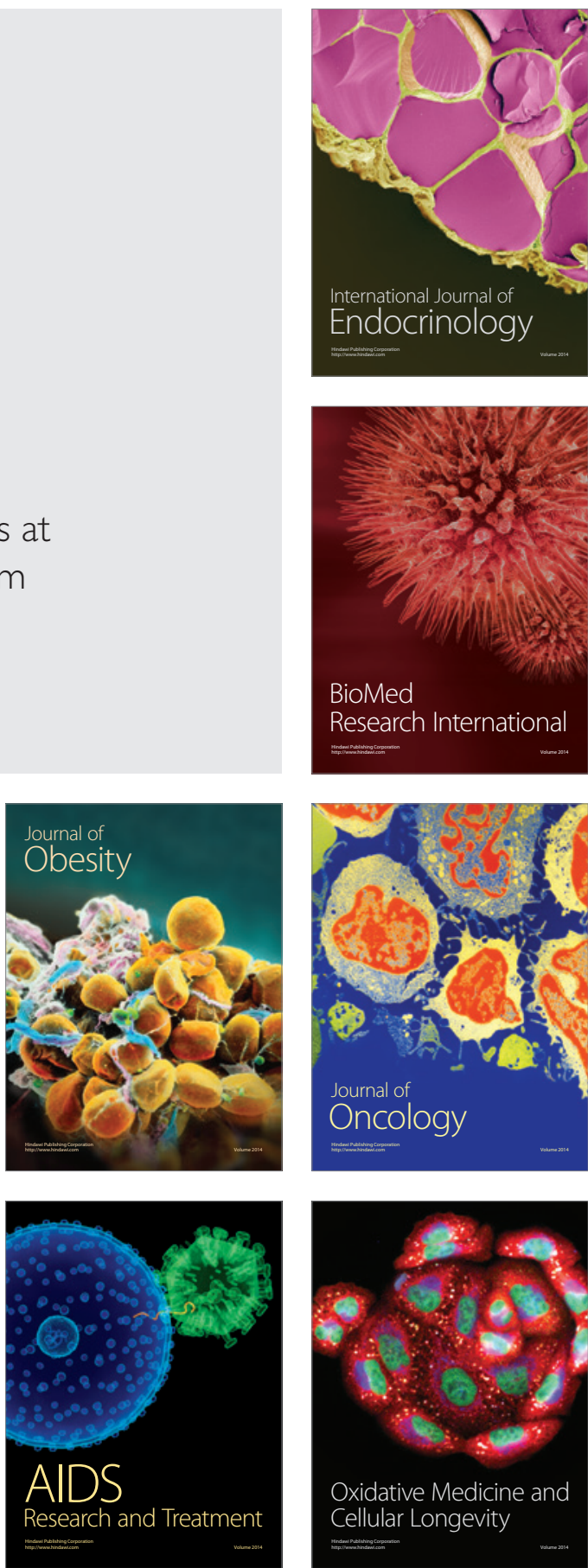